\title{
In-Situ Surface Modification of Terpinen-4-ol Plasma Polymers for Increased Antibacterial Activity
}

\author{
Avishek Kumar ${ }^{1}$, Ahmed Al-Jumaili ${ }^{1}{ }^{10}$, Kateryna Bazaka ${ }^{1,2,3}$, Peter Mulvey ${ }^{4}$, Jeffrey Warner ${ }^{5}$ \\ and Mohan V. Jacob 1,*(D) \\ 1 Electronics Materials Lab, College of Science and Engineering, James Cook University, \\ Townsville 4811, Australia; Avishek.Kumar@my.jcu.edu.au (A.K.); \\ Ahmed.Aljumaili@my.jcu.edu.au (A.A.-J.); Katia.Bazaka@anu.edu.au (K.B.) \\ 2 Institute for Future Environments, Queensland University of Technology, Brisbane 4000, Australia \\ 3 Research School of Electrical, Energy and Materials Engineering, The Australian National University, \\ Canberra 2601, Australia \\ 4 AITHM, Immunology \& Infectious Disease, Australian Institute of Tropical Health \& Medicine, James Cook \\ University, Townsville 4811, Australia; Peter.Mulvey@jcu.edu.au \\ 5 Discipline of Biomedicine, College of Public Health, Medical and Veterinary Sciences, James Cook University, \\ Townsville 4811, Australia; Jeffrey.Warner@jcu.edu.au \\ * Correspondence: Mohan.Jacob@jcu.edu.au
}

Received: 17 November 2019; Accepted: 14 January 2020; Published: 27 January 2020

check for updates

\begin{abstract}
Surface modification of thin films is often performed to enhance their properties. In this work, in situ modification of Terpinen-4-ol (T4) plasma polymer is carried out via simultaneous surface functionalization and nanoparticle immobilization. Terpinen-4-ol plasma polymers surface were decorated with a layer of $\mathrm{ZnO}$ nanoparticles in an oxygen plasma environment immediately after polymer deposition. A combination of hydrophilic modification and $\mathrm{ZnO}$ nanoparticle functionalization of the T4 polymer surface led to an enhancement in antibacterial properties by factor of 3 (from 0.75 to 0.25 CFU. $\mathrm{mm}^{-2}$ ). In addition, $\mathrm{ZnO}$ nanoparticle-modified coatings demonstrated improved UV absorbing characteristics in the region of 300-400 $\mathrm{nm}$ by $60 \%$ relative to unmodified coatings. The $\mathrm{ZnO}$ modified coatings were transparent in the visible region of $400-700 \mathrm{~nm}$. The finding points towards the potential use of $\mathrm{ZnO}$ nanoparticle-modified $\mathrm{T} 4$ plasma polymers as optically transparent UV absorbing coatings.
\end{abstract}

Keywords: in-situ polymer surface modification; $\mathrm{ZnO}$ functionalization; plasma polymers; antibacterial coatings

\section{Introduction}

Bacterial adhesion to material surface is the primary step in biofilm development. Biofilm formation can potentially have severe health and industrial repercussions [1,2], with examples including implant-associated infections [3,4] and marine fouling of environmental sensors, pontoons [5-7]. Planktonic cells of many microbial species have a tendency to form a biofilm matrix on surfaces as a means of protection against hostile environment and predation. Once the biofilm enters the tertiary phase of development, killing of biofilm-residing cells, and biofilm dissolution and removal become challenging. According to some estimates, between 2001 and 2007, hospital acquired infections (HAI) have cost US hospitals $\$ 40$ billion yearly [8].

Surface modification of materials has been frequently used to minimize microbial adhesion $[9,10]$. Surfaces functionalized with enzymes, antibiotics and biocides have also been used in the effort to combat microbial attachment [11-13]. Hydrophilic/hydrophobic modification and immobilization of nanoparticles (Nps), such as $\mathrm{Cu}, \mathrm{ZnO}$, and $\mathrm{Ag}$, onto the surface of material have been used separately 
as an effective strategy to reduce biofilm formation [14-18]. Surfaces modified to display hydrophilic behavior have shown superior antifouling properties [19-21]. Hydrophilic surfaces form hydrogen bonds with water molecules, leading to the formation of a hydration layer at the water/surface interface. This hydration layer acts as an energetic barrier and prevents the adhesion of fouling molecules. For example, Wu et al. used atom transfer radical polymerization to impart hydrophilicity on silicon surfaces using N-vinylpyrrolidone (PVP). The Si-PVP surfaces were characterized by a low water contact angle of $24^{\circ}$ and showed reduced adsorption of human serum albumin, lysosome and fibrinogen by 93,81 and 71\%, respectively [22]. Poly (ethylene glycol) (PEG) has been widely used for hydrophilic modification of surfaces for antifouling applications. PEG functionalized surfaces have been widely used for the development of safer central venous catheters [21], hemodialysis membranes [23], and biosensors and biochips [24,25].

Surface modification techniques such as block co-polymerization [26,27], covalent grafting of hydrophilic groups to surfaces [28], nanoparticle functionalization [29,30], atom transfer radical polymerization [31], Radio Frequency plasma deposition and modifications of surfaces have been used to fabricate surfaces showing antifouling properties. Kim et al. modified nanofiltration thin film composite membranes to be more hydrophilic by a treatment with $\mathrm{NH}_{3}$ plasma. The membranes showed superior antifouling properties on account of their increased hydrophilicity [32].

Nanoparticles have found wide bio application on account of, among many other attributes, their broad spectrum antibacterial activity [33,34]. Among a wide range of particles, zinc oxide nanoparticles have demonstrated enhanced antibacterial and antifouling properties [35,36]. Incorporation of $\mathrm{ZnO}$ nanoparticles into a polymer matrix such as that of polyvinylidene fluoride (PVDF) [37], polysulfide (PSF) [38] and polyethersulfone (PES) [39] enhanced the antifouling activity of these polymer matrices when used as ultrafiltration membranes. Chitosan- $\mathrm{ZnO}$ nanocomposites have demonstrated an effective marine antifouling activity against Pseudoalteromonas nigrifaciens bacteria and the diatom Navicula sp. [40].

Terpinen-4-ol plasma polymers are a recent entry in the range of biodegradable polymer materials that show promising antimicrobial activity and have both biomedical and marine applications [7,41-43]. This study investigates the effect of surface modification of terpinen-4-ol plasma polymers via in-situ hydrophilic modification via oxygen plasma treatment and $\mathrm{ZnO}$ nanoparticle $(\mathrm{Np})$ immobilization on antibacterial activity against Escherichia coli. Typically, plasma enhanced chemical vapor deposition (PECVD) of $\mathrm{ZnO}$ films requires high processing temperatures [44]. However, Terpinen-4-ol plasma polymers will lose their antimicrobial property if deposited at a high temperature due to excessive loss of original chemical functionality of the monomer. The approach used in this study overcomes this challenge by proposing a method by which the desired antimicrobial property of terpinen-4-ol can be retained and further enhanced by $\mathrm{ZnO} \mathrm{Np}$ immobilization and surface wettability modification of the polymer.

\section{Film Fabrication and Characterization}

\subsection{Materials}

Terpinen-4-ol $\left(\mathrm{C}_{10} \mathrm{H}_{18} \mathrm{O}, \mathrm{Mw}=154.24 \mathrm{~g} / \mathrm{mol}\right.$, Purity > 99\%) and zinc acetylacetonate $\left(\mathrm{Zn}(\mathrm{acac})_{2}\right)$ were purchased from (Australian Botanical Products, Hallam, Australia) and (Sigma Aldrich, St.Louis, MO, USA), respectively, and used without any further modification. Microscope glass cover slips ( $\Phi=19 \mathrm{~mm}$, ProSciTech, Kirwan, Australia) and silicon wafers (University Wafer, Boston, MA, USA) were used as substrates onto which the polymer was deposited. The substrates were cleaned in ultrasonic bath for $30 \mathrm{~min}$ in 5\% solution of Decon 90 (Decon Laboratories Limited, King of Prussia, PA, USA), followed by double distilled water, acetone and propanol. High purity oxygen and argon gas (purity $>99.9 \%$ ) were procured from BOC Gas, Townsville, Australia.

\subsection{Thin Film Fabrication}

$\mathrm{ZnO}$ nanoparticle-functionalized terpinen-4-ol films were fabricated in a custom built capacitively coupled tubular (Quartz, $1=80 \mathrm{~cm}, \mathrm{~d}=5 \mathrm{~cm}$ ) radio frequency reactor $(13.56 \mathrm{MHz}$, Advanced Energy, Fort 
Collins, CO, USA). Electrode separation was maintained at $8 \mathrm{~cm}$ for all the depositions. Substrates were placed $1 \mathrm{~cm}$ away from the leading electrode. Zinc acetyl acetonate hydrate $\left[\mathrm{Zn}_{(}\left(\mathrm{C}_{5} \mathrm{H}_{7} \mathrm{O}_{2}\right)_{2} \times \mathrm{H}_{2} \mathrm{O}\right]$ was placed in the clean ceramic boat and loaded in the middle of the reactor. External heating was used to vaporize $\mathrm{Zn}$ (acac) 2 at a temperature of $140{ }^{\circ} \mathrm{C}$. No external substrate heating was used during the deposition. A schematic of plasma polymerization apparatus and chemical structure of monomer is shown in Figure 1. The substrate temperature was found to be $40{ }^{\circ} \mathrm{C}$ during $\mathrm{ZnO} \mathrm{Np}$ immobilization onto terpinen-4-ol surfaces. Terpinen-4-ol monomer flow rate was kept constant at $29 \mathrm{~cm}^{3} / \mathrm{min}$. The polymerization of terpinen-4-ol was carried out at $10 \mathrm{~W}$ and the process pressure of $5 \times 10^{-2}$ mbar. Terpinen-4-ol plasma polymers deposited at power of $10 \mathrm{~W}$ have been found to retain their inherent antimicrobial properties. Films deposited at higher power than $10 \mathrm{~W}$ have shown no antimicrobial properties, whereas one deposited at lower power are unstable under aqueous conditions $[7,45]$. A fine-tuning of plasma power, process pressure, and flow rate have been found to deposit a Terpinen-4-ol plasma polymer retaining a maximum antimicrobial property of the monomer. Either argon or oxygen were used as a carrier gas with latter providing hydrophilic modification of the surface of the as-deposited terpinen4-ol polymer matrix. Deposition of T4 monomer alone in either oxygen or argon plasma led to the wettability modification imparting hydrophilic/hydrophobic character to T4 polymer as compared to T4 polymer deposited in absence of carrier gas. Passing $\mathrm{Zn}(\mathrm{acac})_{2}$ vapor over the freshly deposited polymer led to in situ functionalization of the surface with ZnO nanoparticles. Flow rate of the argon and oxygen carrier gas was kept constant at $6 \mathrm{~cm}^{3} / \mathrm{min}$. The desired thickness of the polymer was achieved by adjusting the deposition time.

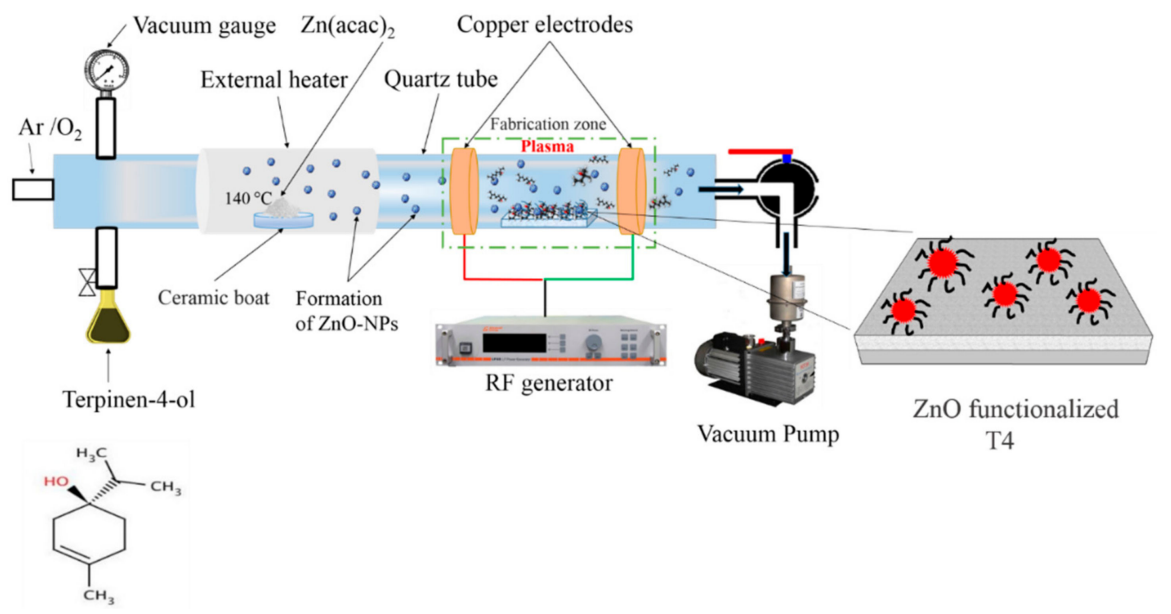

Figure 1. Schematic of plasma polymerization apparatus setup.

\subsection{Thin Film Characterization}

Film thickness was estimated by spectroscopic ellipsometry (VASE J. A. Woollam, M2000 D, Lincoln, NE, USA). Measurements were performed in the wavelength range of 200-1000 $\mathrm{nm}$ at three different angle of incidence $\left(55^{\circ}, 60^{\circ}\right.$ and $\left.65^{\circ}\right)$. The film thickness were modelled using Cauchy function. The morphology of the films was characterized by field emission scanning electron microscopy at 10 KV (FE-SEM, Hitachi SU 500, Tokyo, Japan). The chemical composition of the films was estimated by FT-IR spectroscopy (PerkinElmer, Waltham, MA, USA; Spectrum 100, Staten Island, NY, USA) in Attenuated Total Reflectance (ATR) mode. Films were deposited on Potassium bromide (KBR) pellets for ATR-FTIR characterization and spectra were obtained at resolution of $4 \mathrm{~cm}^{-1}$ averaged over 124 scans. All the acquired FT-IR data were thickness normalized. Hydrophilic/hydrophobic character of the films was determined by static contact angle measurement by means of a goniometer (KSV CAM 101, KSV instruments, Helsinki, Finland) using three liquids (Water, Ethane diol, Di-iodomethane). Five measurements were performed per sample averaged over five samples using a drop volume of $3 \mu \mathrm{L}$. The Young-Laplace fitting and Van-Oss-Chaudhury-Good method was used to get contact angle and surface energy values, respectively. 
Raman spectra of the films were acquired with a confocal Raman microscope (Witec Alpha 300 Access, WITec GmBH, Ulm, Germany). The Raman spectra were recorded in the range of $100-4000 \mathrm{~cm}^{-1}$. Surface roughness parameters were examined using atomic force microscopy in a tapping mode using Atomic force microscopy (NT-MDT Spectrum Instruments, Zelenograd Moscow, Russian Federation). The average roughness was measured for $3 \mu \mathrm{m} \times 3 \mu \mathrm{m}$ image collected at room temperature.

\subsection{Bacterial Assay}

Antibacterial activity of films was evaluated against E. coli (ATCC-924). E. coli cells were cultured in Luria-Betani (LB) broth at $37^{\circ} \mathrm{C}$ for $24 \mathrm{~h}$ to reach the log phase. The bacterial solution was diluted to $5 \times 10^{5}$ colony forming units (CFU)/mL. The coated and uncoated glass substrates (control) were sterilized by subsequent washing in ethanol and phosphate-buffered saline (PBS) solution. The sterilized films and controls were placed into 12-well cell culture plates (Falcon Laboratories, Colorado Springs, CO, USA). In addition, $2 \mathrm{~mL}$ of $E$. coli suspension was placed onto samples into each well and incubated at $37^{\circ} \mathrm{C}$ for $24 \mathrm{~h}$. Each sample was gently washed once with $10 \mathrm{~mL}$ of sterile PBS [46] and placed into $50 \mathrm{~mL}$ polyethylene tubes containing $5 \mathrm{~mL}$ of sterile PBS solution. Tubes were sonicated for $5 \mathrm{~min}$ to detach bacterial cells. Furthermore, $10 \mu \mathrm{L}$ of bacterial suspension was added to $90 \mu \mathrm{L}$ of prewarmed LB broth. In addition, $100 \mu \mathrm{L}$ of the diluted bacterial suspension was plated onto nutrient agar. Agar plates were brooded at $37^{\circ} \mathrm{C}$ for $24 \mathrm{~h}$, and the number of CFU were counted. All tests were carried out with three replicates.

\section{Results and Discussion}

\subsection{Deposition Rate}

Wettability and $\mathrm{ZnO}$ modification of $\mathrm{T} 4$ was carried out via plasma enhanced chemical vapor depositions (PECVD). Deposition rate of 17.43, $32.67 \mathrm{~nm} \mathrm{~min}^{-1}$ was found for T4 plasma polymers deposited using Argon and Oxygen as carrier gas, respectively. Deposition rate of T4 in the absence of any carrier gas and during in-situ $\mathrm{ZnO}$ functionalization was 14.7 and $30.15 \mathrm{~nm} \mathrm{~min}^{-1}$, respectively. The thickness of prepared plasma polymer film was kept constant at $300 \mathrm{~nm}$ by varying deposition time. Silicon wafers were used as substrates during deposition. Deposition rates $\left(R_{d}\right)$ of coatings are shown in Figure 2. The deposition rate of the T4 in the absence of carrier gas is also shown for comparison. As seen in Figure 2, $R_{d}$ in oxygen plasma is higher than in the Ar plasma. The higher effective flow rate $\left(\mathrm{F}=\mathrm{F}_{\mathrm{m}}+\mathrm{aF}_{\mathrm{c}}\right)$ of gases $\left(\mathrm{O}_{2}+\mathrm{T} 4\right.$ monomer $)$ in oxygen plasma contributes to higher $\mathrm{R}_{\mathrm{d}}$. Formation of oxygen radicals and their reaction with film-forming species enhance the deposition rate. In addition, the correction flow factor $a$ in the above equation is 0.6 for the oxygen and (0.05-0.1) for argon [47]. Argon when used as a carrier gas in PECVD has been found to increase the monomer fragmentation [48]; however, the deposition mechanism remains unaffected [49].

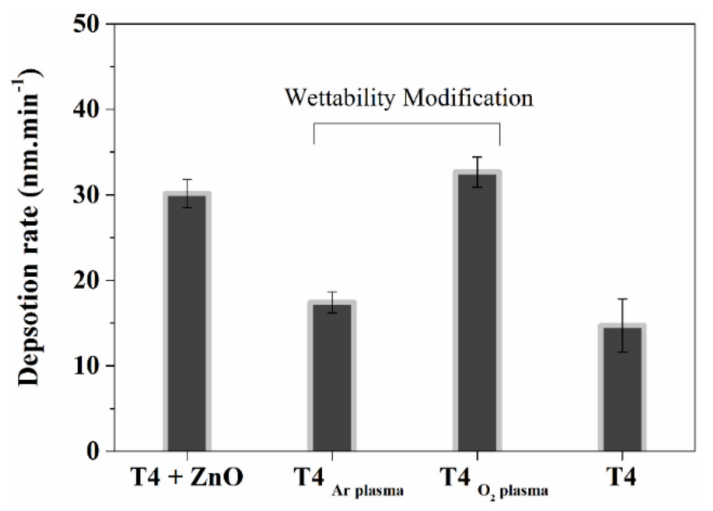

Figure 2. Deposition rate of $\mathrm{T} 4$ on silicon wafer substrate during wettability and nanoparticle modification. Deposition in either argon or oxygen plasma led to wettability modification. $\mathrm{ZnO}$ nanoparticle functionalization of $\mathrm{T} 4$ polymers is carried in $\mathrm{O}_{2}$ plasma. 


\subsection{Film Composition}

Figure 3a shows the Attenuated total reflection-Fourier-transform infrared spectroscopy (ATR-FTIR) spectra of all modified T4 films. The FTIR spectrum of T4-ZnO nanocomposite shows the characteristic peaks at 1590,1521,1448, 1390 and $1254 \mathrm{~cm}^{-1}$. The peaks occurring at these positions are characteristic of pp-Zn(acac $)_{2}$ [50]. The appearance of the band at $1710 \mathrm{~cm}^{-1}$ in all the deposited films is indicative of the formation of $-\mathrm{C}=\mathrm{O}$ group during deposition, irrespective of the surface modification. The $\mathrm{T}_{\mathrm{O} 2}$ plasma and $\mathrm{T} 4_{\text {Ar plasma }}$ films show the characteristic peaks at $2800-3000 \mathrm{~cm}^{-1}$ (aliphatic $\mathrm{C}-\mathrm{H}$ stretching) and $3400 \mathrm{~cm}^{-1}$ (O-H stretching vibration). The intensity of the above peaks $\left(2800-3000 \mathrm{~cm}^{-1}\right)$ is greatly reduced in the case of $\mathrm{T} 4-\mathrm{ZnO}$ nanocomposites. It is interesting to note that there is the formation of carboxylate and conjugated ketone functionalities during $\mathrm{ZnO}$ modification of $\mathrm{T} 4$ in $\mathrm{O}_{2}$ plasma. Attachment of acetylacetonates groups from $\mathrm{Zn}(\mathrm{acac})_{2}$ on $\mathrm{T} 4$ explains their occurrence.
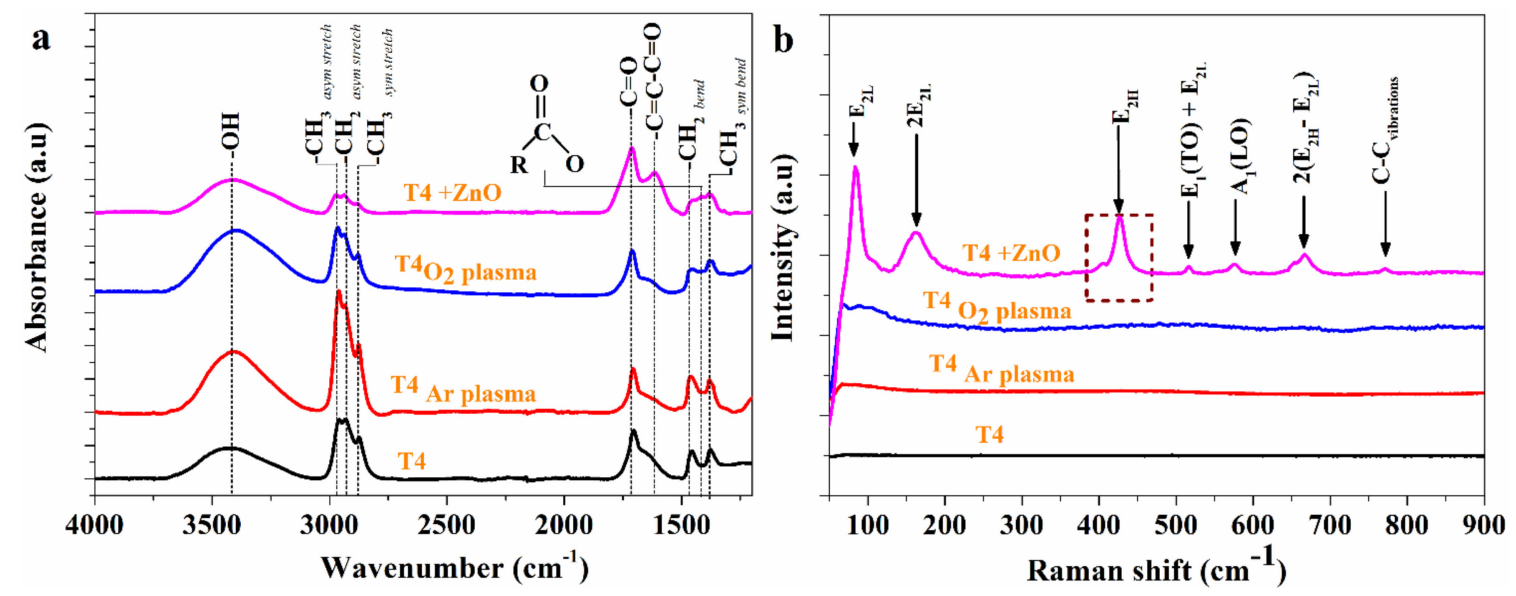

Figure 3. (a) ATR-FTIR spectra of ZnO nanoparticle functionalized and wettability modified T4 surfaces;

(b) Raman spectra of modified T4 surfaces.

Raman spectroscopic studies of the samples was done to get a qualitative estimate of $\mathrm{ZnO}$ nanoparticles in the deposited films. Figure $3 \mathrm{~b}$ represents Raman spectra of $\mathrm{ZnO}$ functionalized T4 films. Spectra of T4 deposited in the absence and presence of carrier gas (either $\mathrm{O}_{2}$ or $\mathrm{Ar}$ ) are also shown for comparison. Wurtzite $\mathrm{ZnO}$ is characterized by a set of eight optical phonons: $\Gamma_{\mathrm{opt}}=\mathrm{A}_{1}+$ $E_{1}+2 E_{2}+2 B_{1} . A_{1}$ and $E_{1}$ are polar, whereas and $E_{2}$ modes are non-polar and Raman active [51,52]. The $\mathrm{E}_{2 \mathrm{H}}$ vibration mode at $440 \mathrm{~cm}^{-1}$ is representative of wurtzite phase of $\mathrm{ZnO}$. The $\mathrm{E}_{2 \mathrm{H}}$ phonon frequency is red shifted by $12 \mathrm{~cm}^{-1}$ in the film (T4 $\left.+\mathrm{ZnO}\right)$. Defect formation [53] on nanoparticles and phonon confinement [54] gives rise to this peak shift. The other peaks at about 83, 400 and $574 \mathrm{~cm}^{-1}$ are representative of $E_{2 L}, A_{1}(T O)$ and $A_{1}(\mathrm{LO})$ fundamental phonon mode of wurtzite $\mathrm{ZnO}$. The other peaks at 514, 666 and $766 \mathrm{~cm}^{-1}$ are assigned to $E_{1}(\mathrm{TO})+\mathrm{E}_{2 \mathrm{~L}}, 2\left(\mathrm{E}_{2 \mathrm{H}}-\mathrm{E}_{2 \mathrm{~L}}\right)$ and $\mathrm{A}_{1}$ $(\mathrm{TO})+\mathrm{E}_{2 \mathrm{~L}}$ multiphoton scattering modes. Most of the Raman peaks of deposited films have been found to be red shifted as compared to the well-established ones in the literature [55]. The bonding of organic $\mathrm{T} 4$ and acetate molecules on $\mathrm{ZnO}$ surface is the possible reason for this lowering of vibrational frequency [56,57].

The thermal decomposition of zinc acetylacetonate hydrate $\left[\mathrm{Zn}\left(\mathrm{C}_{5} \mathrm{H}_{7} \mathrm{O}_{2}\right)_{2} \cdot \mathrm{xH}_{2} \mathrm{O}\right]$ has been found to yield metallic zinc and zinc oxide $[30,58,59]$. The $\mathrm{ZnO}$ can get incorporated into polymer surface as metallic zinc or zinc oxide. At temperature above $110^{\circ} \mathrm{C}$, zinc acetylacetonate hydrate has been found to go through the complex process of decomposition. Initially, there is single step dehydration followed by the phase transition, fusion evaporation and decomposition of anhydrous zinc acetylacetonate [60]. There is a tendency for $\mathrm{ZnO}$ and $\mathrm{Zn}$ particles to segregate in the polymer surface as they have higher cohesive energy than the polymers. When metals are incorporated into the polymer surface, they have been found to go through the various processes. The processes such as desorption, diffusion into bulk 
or random rolling on the surface has been found to occur [60].There is very weak interaction between nanoparticles and polymer surfaces.

\subsection{Coating Wettability}

Water contact angle (WCA) measurements provide information about the hydrophilic/hydrophobic nature of the films. Figure 4 shows the WCA measurements on the modified T4 films along with the surface energy. Table 1 lists contact angles for three liquids on the modified surfaces used for free energy calculations. The contact angles on the surfaces of T4 and control samples are also shown for comparison. It can be observed that deposition in oxygen plasma results in the film with hydrophilic attributes. The $\mathrm{ZnO}$-modified $\mathrm{T} 4$ shows highly hydrophilic character $\left(\mathrm{WCA}<15^{\circ}\right.$ ). Polar character of $\mathrm{ZnO}$ and deposition in oxygen plasma render these films highly hydrophilic. T4 films deposited in argon and in oxygen plasmas exhibited contact angles of $75^{\circ}$ and $40^{\circ}$, respectively. The high proportion of hydrophobic carbonaceous $-\mathrm{CH}_{\mathrm{x}}$ functionalities evident in FTIR spectra explains the increase in the contact angle of T4 deposited in Ar plasma.

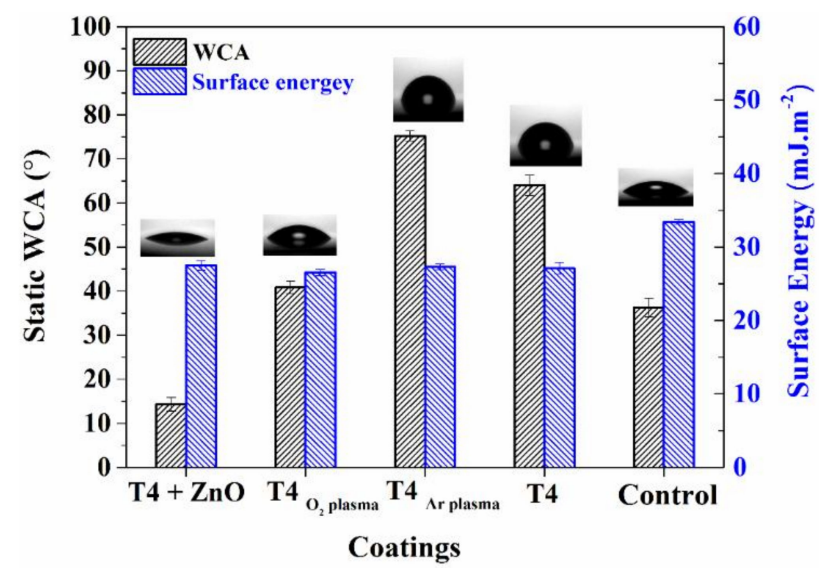

Figure 4. Static water contact angle and surface energy of modified T4 coatings. The inset image shows the contact angle less than $90^{\circ}$. Control consists of glass coverslip.

Table 1. Contact angle of water, ethanediaol, and di-iodomethane on modified T4 surfaces.

\begin{tabular}{cccc}
\hline \multirow{2}{*}{ Coatings } & \multicolumn{3}{c}{ Contact Angle, $^{\circ}$} \\
\cline { 2 - 4 } & Water & Ethane Diol & Di-iodomethane \\
\hline $\mathrm{T} 4+\mathrm{ZnO}$ & $14.28 \pm 0.58$ & $15.96 \pm 1.93$ & $40.75 \pm 0.73$ \\
\hline $\mathbf{T} 4, \boldsymbol{O}_{2}$ & $40.83 \pm 0.36$ & $16.63 \pm 1.11$ & $39.52 \pm 0.77$ \\
\hline $\mathrm{T} 4, \mathrm{Ar}$ & $75.19 \pm 1.18$ & $18.93 \pm 0.57$ & $37.85 \pm 0.37$ \\
\hline $\mathrm{T} 4$ & $65 \pm 2.58$ & $17.85 \pm 3.45$ & $37.83 \pm 2.65$ \\
\hline
\end{tabular}

\subsection{Surface Morphology}

The effect of wettability and nanoparticle modification on surface roughness is shown in Figure 5. The root mean square (R.m.s) roughness of the oxygen and argon plasma deposited and ZnO modified $\mathrm{T} 4$ are $0.16 \mathrm{~nm}, 0.22 \mathrm{~nm}$ and $0.34 \mathrm{~nm}$, respectively. The roughness of T4 without any treatment and of bare silicon substrate are 0.24 and $0.26 \mathrm{~nm}$, respectively. The roughness reported here shows a nanometer scale. The ZnO-modified and Ar deposited T4 films have been found to show a cauliflower structure. However, this cauliflower morphology was not seen in samples deposited under oxygen plasma. The Ar deposited T4 exhibits a slightly increased roughness than that of the oxygen deposited samples. Figure 6 shows the SEM images of $\mathrm{ZnO}$ modified T4 films taken at various magnifications. The size of the nanoparticles ranged from 60 to $90 \mathrm{~nm}$. Ball like $\mathrm{ZnO}$ nanoparticles were created according to growth conditions. 


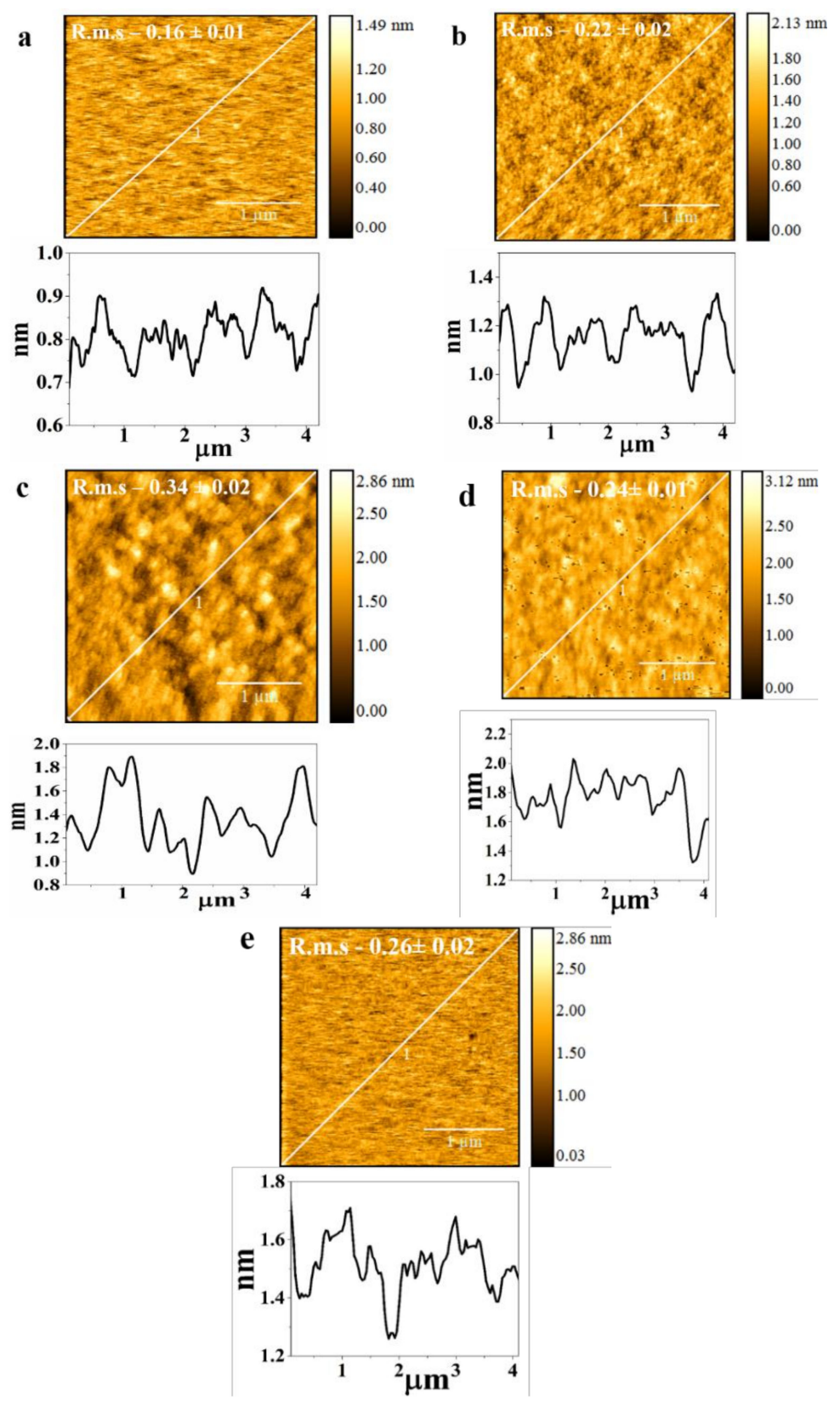

Figure 5. AFM images of (a) $\mathrm{T} 4 \mathrm{O} 2$ plasma, R.m.s $=0.16 \pm 0.01 \mathrm{~nm}$; (b) $\mathrm{T} 4$ Ar plasma, R.m.s $=0.16 \pm 0.02 \mathrm{~nm}$; (c) $\mathrm{T} 4+\mathrm{ZnO}$, R.m.s $=0.34 \pm 0.02 \mathrm{~nm}$; (d) T4, R.m.s $=0.24 \pm 0.01$; (e) Silicon substrate, R.m.s $=0.26 \pm 0.02$. Scanning area $3 \mu \mathrm{m} \times 3 \mu \mathrm{m}$. Line profiles of surfaces are also shown.
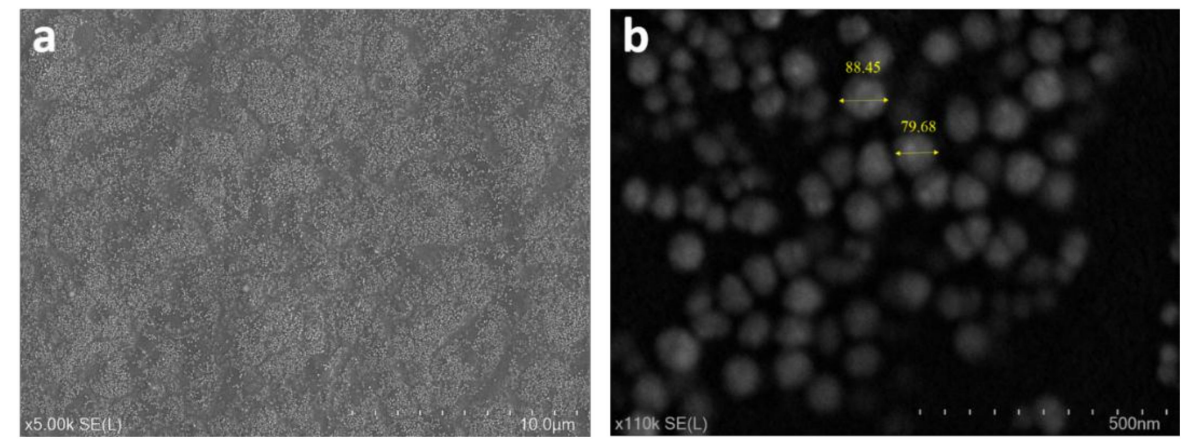

Figure 6. SEM images of $\mathrm{ZnO}$ modified $\mathrm{T} 4$ plasma polymers at different magnification of, $(\mathbf{a}) \times 5 \mathrm{~K}$ and (b) $\times 110 \mathrm{~K}$. 


\subsection{Light Transmission Efficiency}

Transparency to visible light and UV absorption of modified T4 film were measured within 200-1000 nm range. The transmittance spectra of the modified films are shown in Figure 7. T4 films functionalized with $\mathrm{ZnO}$ nanoparticles showed significant UV-blocking in the 300-400 nm region. $\mathrm{UV}$ absorption by $\mathrm{ZnO}$ nanoparticles seems to be a possible explanation for this phenomenon. It is also worthwhile to note that the rate of decrease in UV light transmission is higher than that of visible light. This rate of decrease is shown in the inset graph, where $m$ denotes the slope of the graph in the particular region as marked by the green line. Thus, the UV blocking property of this film can be further enhanced by increasing the $\mathrm{ZnO}$ concentration on the film surface. Thin films with high UV absorption and visible light transmission have a potential application as optically transparent food packaging materials and there are many other applications [61,62]. Light transmission in the visible range of $400-700 \mathrm{~nm}$ is greater than $90 \%$ for T4 films deposited in argon and oxygen plasmas. The oxygen plasma-deposited T4 exhibited some UV blocking property, though it was significantly lower compared to $\mathrm{ZnO}$-functionalized T4 films.

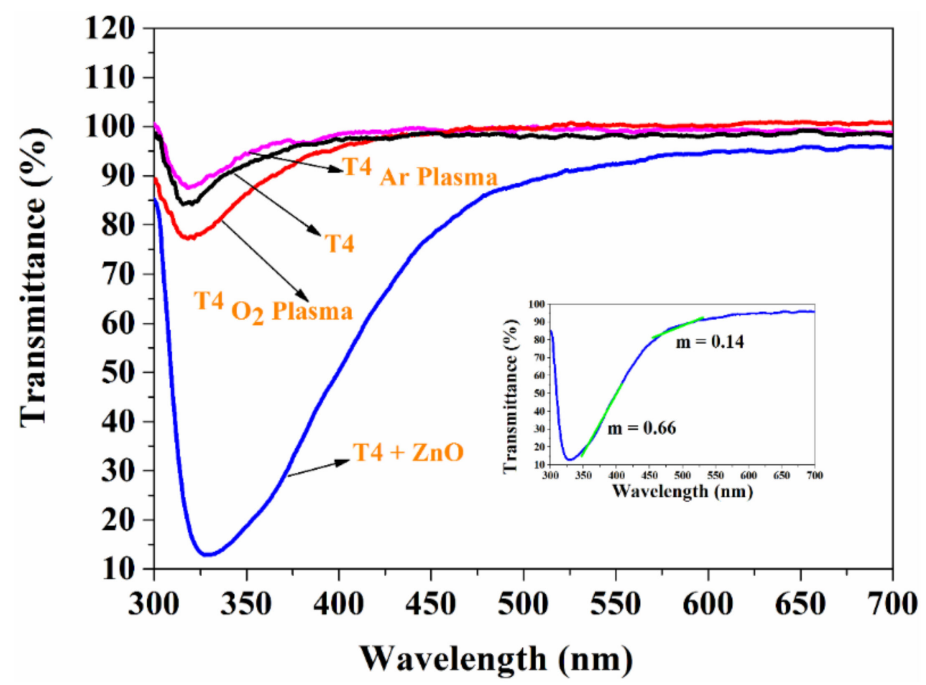

Figure 7. UV-visible spectra of modified T4 films. Inset graph shows the rate of decrease of UV and visible light transmission in two different regions between 300-400 nm and 450-600 nm.

\subsection{Thermal Degradation Behaviour}

Thermal stability of modified T4 films was studied using in-situ dynamic ellipsometry [63]. A linear fit to acquired data over two temperature ranges was performed using the least square fit method. The glass transition temperature $\left(T_{g}\right)$ was determined by the intersection of two fitted lines. Figure 8 shows the percentage thickness loss as a function of temperature. Three kinds of thermal degradation regimes were observed for modified T4 films. Thermal degradation profile of the pristine $\mathrm{T} 4$ is also included for comparison. In the temperature regime of $50-90^{\circ} \mathrm{C}$, the rate of thickness loss was well below $20 \%$ for all the deposited films. Loss of trapped moisture and unbound species from the surface may explain this observation. Major thickness loss is observed in the temperature regime of $90-160^{\circ} \mathrm{C}$. This observation can be associated with cleavage of hydroxyl groups, decarboxylation reactions, and breaking of aliphatic carbon chains. The degradation phenomena above $170{ }^{\circ} \mathrm{C}$ can be attributed to breaking of carbon-carbon linkages. The inset in the graph shows the estimated $\mathrm{T}_{\mathrm{g}}$ of modified $\mathrm{T} 4$ plasma polymers. The $\mathrm{T}_{\mathrm{g}}$ of the modified $\mathrm{T} 4$ plasma polymer was found to increase in the following order, $\mathrm{T} 4$ Ar plasma $<\mathrm{T} 4 \mathrm{O}_{2}$ plasma $<\mathrm{T} 4<\mathrm{T} 4+\mathrm{ZnO}$. This trend in $\mathrm{T}_{\mathrm{g}}$ gives an insight into the chain length in the deposited polymers. The chain length is expected to follow the similar trend as $\mathrm{T}_{\mathrm{g}}$. During deposition, higher T4 fragmentation occurs in argon plasma rather than in the oxygen plasma [48]. In addition, less T4 fragmentation is found when depositing without any carrier gases as evident from the trend above. 


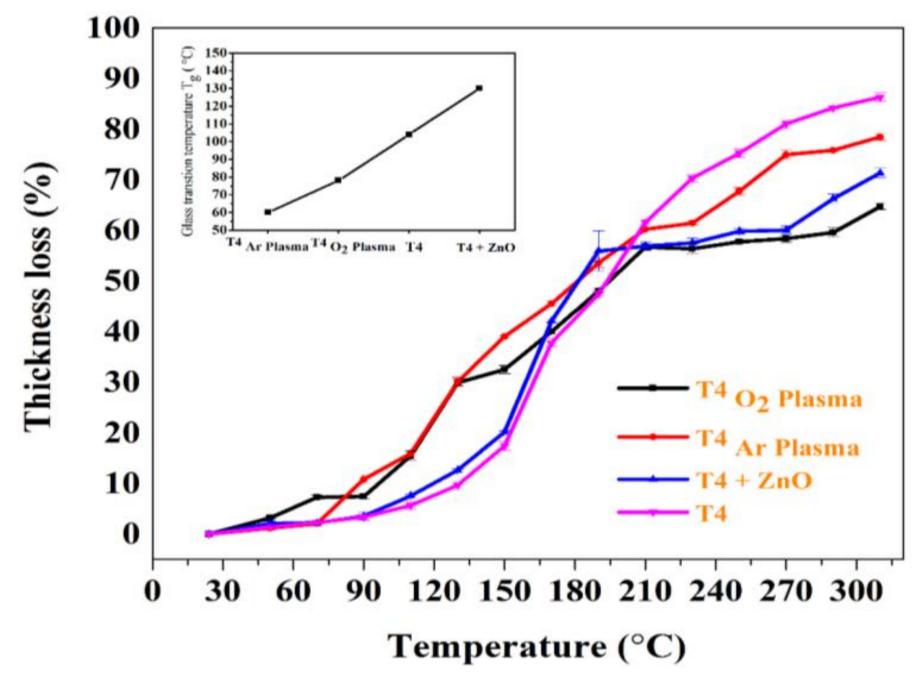

Figure 8. Percentage thickness loss as a function of temperature estimated using ellipsometry data. The inset shows the glass transition temperature $\mathrm{T}_{\mathrm{g}}$ of modified $\mathrm{T} 4$ plasma polymers. $\mathrm{T}_{\mathrm{g}}$ was found to increase in the following manner $\mathrm{T} 4$ Ar plasma $<\mathrm{T} 4 \mathrm{O} 2$ plasma $<\mathrm{T} 4<\mathrm{T} 4+\mathrm{ZnO}$.

\subsection{Antibacterial Test}

Antibacterial activity of modified terpinen-4-ol surfaces was tested against E. coli cells. Initial adhesion up to $24 \mathrm{~h}$ was examined as it is the preliminary step in biofilm formation. Figure $9 \mathrm{a}$ shows the bacteria that survived after $24 \mathrm{~h}$ exposure to modified T4 surfaces and control. The small white dots are representative of $E$. coli colonies on agar culture plates. Figure $9 \mathrm{~b}$ shows the colony forming unit (C.F.U.) $/ \mathrm{mm}^{2}$ for all the modified T4 surfaces. All the modified T4 plasma polymers showed significant reduction in bacterial adhesion w.r.t control $(p<0.05)$. It can be observed that the T4 $+\mathrm{ZnO}$ and hydrophilic $\mathrm{T}_{\mathrm{O}} 2$ plasma surface exhibited a significant improvement in antibacterial activity w.r.t. pristine $\mathrm{T} 4(p<0.05)$. The $\mathrm{ZnO}$ modified $\mathrm{T} 4$ demonstrated stronger antibacterial activity than $\mathrm{T} 4_{\mathrm{O} 2}$ plasma, $\mathrm{T} 4_{\mathrm{Ar}}$ plasma and $\mathrm{T} 4$ films. In addition, $\mathrm{T} 4_{\mathrm{Ar} \text { plasma }}$ which is slightly hydrophobic showed more bacterial adhesion when compared to T4.

The combined effect of the hydrophilic surface along with the antimicrobial properties of $\mathrm{T} 4$ and $\mathrm{ZnO}$ is the possible reason for enhanced antibacterial performance of the $\mathrm{T} 4_{\mathrm{O} 2}$ plasma and $\mathrm{T} 4+\mathrm{ZnO}$ polymers. Microorganism approaching the surface would find it difficult to settle on the surface due to the hydration layer formed between the surface and adjacent water molecules in the first place. This would be followed by the killing of any attached microorganism by $\mathrm{ZnO}$ nanoparticles and $\mathrm{T} 4$ molecules. The internalization of $\mathrm{ZnO}$ nanoparticles by cells is found to induce oxidative stress, resulting in their death [64,65]. In addition, T4 molecules have the ability to compromise the cell membrane structure, inhibiting their growth resulting in the cell death $[66,67]$.

a

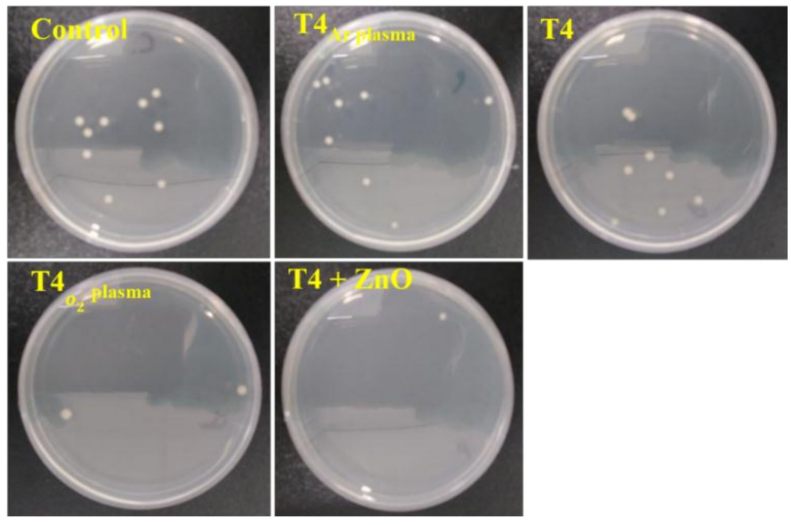

Figure 9. Cont. 


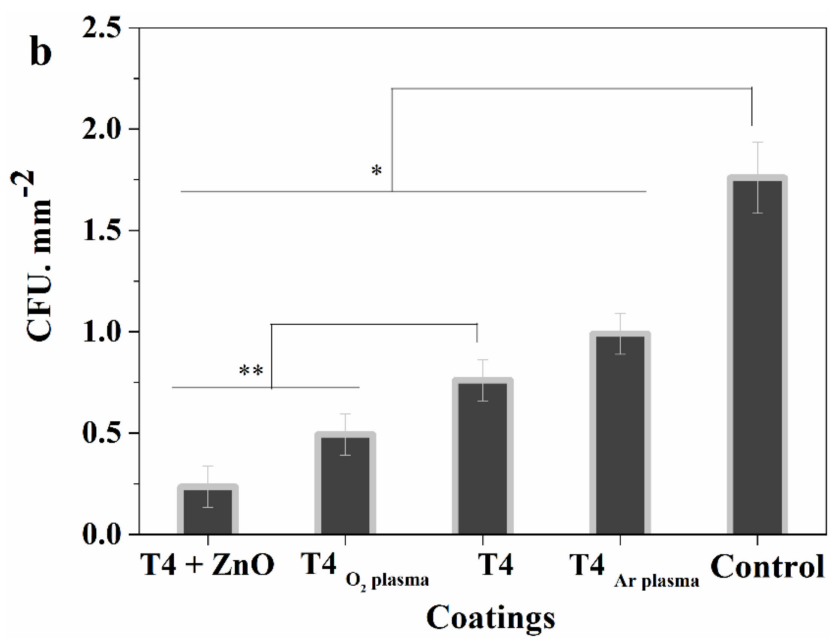

Figure 9. (a) photographs of E. coli colonies on agar culture plates after $24 \mathrm{~h}$ incubation on various T4 coatings; (b) colony forming units $/ \mathrm{mm}^{2}$ on modified T4 surfaces and the control. All T4 surfaces showed a significant reduction in bacterial adhesion w.r.t. control $(* p<0.05)$. $\mathrm{T} 4+\mathrm{ZnO}$ and $\mathrm{T} 4$ $\mathrm{O} 2$ plasma demonstrated a significant reduction in bacterial adhesion w.r.t. to T4 (** $p<0.05)$.

\section{Conclusions}

The use of argon and oxygen as a carrier gas had a profound influence on the deposition rate and degree of fragmentation of terpinen-4-ol during PECVD. Deposition in argon plasma leads to enhanced monomer fragmentation as compared to deposition occurring in oxygen plasma or in the absence of any carrier gas. This is also evidenced by the lowest $\mathrm{T}_{\mathrm{g}}$, which is observed for $\mathrm{T} 4_{\mathrm{Ar}}$ plasma . Chemical composition of terpinen-4-ol films deposited using either argon or oxygen as a carrier gas was found to be similar but varied in their relative peak magnitude. The ratio of $-\mathrm{CH}_{\mathrm{x}} /-\mathrm{OH}$ group was greater in T4 films deposited in argon plasma than that in oxygen plasma. The difference in the proportion of functional group influenced the wettability of T4 films. Films rich in -OH content showed higher hydrophilic character. The oxygen plasma-modified and ZnO-modified T4 plasma polymers demonstrated enhanced antibacterial activity against E. coli. ZnO-modified T4 showed the most effective antibacterial activity among all the modified T4 coatings. Highly hydrophilic character combined with the antimicrobial effect of $\mathrm{T} 4$ and $\mathrm{ZnO}$ seems to be the possible explanation for this observation. Meanwhile ZnO-modified T4 coatings also showed significant UV absorption. However, as compared to unmodified $\mathrm{T} 4$ coatings, hydrophilic and $\mathrm{ZnO}$ nanoparticle modification played an important role in the enhancement of antimicrobial activity of T4 plasma polymers.

Author Contributions: Conceptualization, M.V.J. and A.K; Data curation, A.A.-J.; Formal analysis, P.M. and J.W.; Writing—original draft, A.K.; Writing—review \& editing, K.B. All authors have read and agreed to the published version of the manuscript.

Funding: A.K. and K.B. are grateful for financial support from the Australian Research Council (DE130101550).

Conflicts of Interest: The authors declare no conflict of interest.

\section{References}

1. Bixler, G.D.; Bhushan, B. Biofouling: Lessons from nature. Phil. Trans. R. Soc. A 2012, 370, $2381-2417$. [CrossRef] [PubMed]

2. Leslie, D.C.; Waterhouse, A.; Berthet, J.B.; Valentin, T.M.; Watters, A.L.; Jain, A.; Kim, P.; Hatton, B.D.; Nedder, A.; Donovan, K. A bioinspired omniphobic surface coating on medical devices prevents thrombosis and biofouling. Nat. Biotechnol. 2014, 32, 1134. [CrossRef] [PubMed]

3. Romanò, C.L.; Romanò, D.; Morelli, I.; Drago, L. The concept of biofilm-related implant malfunction and "low-grade infection". In A Modern Approach to Biofilm-Related Orthopaedic Implant. Infections; Springer: Cham, Switzerland, 2016; pp. 1-13. 
4. Zimmerli, W. Clinical presentation and treatment of orthopaedic implant-associated infection. J. Intern. Med. 2014, 276, 111-119. [CrossRef] [PubMed]

5. Dafforn, K.; Johnston, E.; Glasby, T. Shallow moving structures promote marine invader dominance. Biofouling 2009, 25, 277-287. [CrossRef]

6. Delauney, L.; Compere, C.; Lehaitre, M. Biofouling protection for marine environmental sensors. Ocean Sci. 2010, 6, 503-511. [CrossRef]

7. Kumar, A.; Mills, S.; Bazaka, K.; Atkinson, I.; Jacob, M.V. Biodegradable optically transparent terpinen-4-ol thin films for marine antifouling applications. Surf. Coat. Technol. 2018, 349, 426-433. [CrossRef]

8. Hassan, M.; Tuckman, H.P.; Patrick, R.H.; Kountz, D.S.; Kohn, J.L. Cost of hospital-acquired infection. Hosp. Top. 2010, 88, 82-89. [CrossRef]

9. Ren, X.; Feng, Y.; Guo, J.; Wang, H.; Li, Q.; Yang, J.; Hao, X.; Lv, J.; Ma, N.; Li, W. Surface modification and endothelialization of biomaterials as potential scaffolds for vascular tissue engineering applications. Chem. Soc. Rev. 2015, 44, 5680-5742. [CrossRef]

10. Bazaka, K.; Jacob, M.; Chrzanowski, W.; Ostrikov, K. Anti-bacterial surfaces: Natural agents, mechanisms of action, and plasma surface modification. RSC Adv. 2015, 5, 48739-48759. [CrossRef]

11. Ivanova, K.; Fernandes, M.M.; Francesko, A.; Mendoza, E.; Guezguez, J.; Burnet, M.; Tzanov, T. Quorum-quenching and matrix-degrading enzymes in multilayer coatings synergistically prevent bacterial biofilm formation on urinary catheters. ACS Appl. Mater. Interf. 2015, 7, 27066-27077. [CrossRef]

12. Ashbaugh, A.G.; Jiang, X.; Zheng, J.; Tsai, A.S.; Kim, W.-S.; Thompson, J.M.; Miller, R.J.; Shahbazian, J.H.; Wang, Y.; Dillen, C.A. Polymeric nanofiber coating with tunable combinatorial antibiotic delivery prevents biofilm-associated infection in vivo. Proc. Natl. Acad. Sci. USA 2016, 113, E6919-E6928. [CrossRef] [PubMed]

13. Salwiczek, M.; Qu, Y.; Gardiner, J.; Strugnell, R.A.; Lithgow, T.; McLean, K.M.; Thissen, H. Emerging rules for effective antimicrobial coatings. Trends Biotechnol. 2014, 32, 82-90. [CrossRef] [PubMed]

14. Desrousseaux, C.; Sautou, V.; Descamps, S.; Traoré, O. Modification of the surfaces of medical devices to prevent microbial adhesion and biofilm formation. J. Hosp. Infect. 2013, 85, 87-93. [CrossRef] [PubMed]

15. Gao, G.; Lange, D.; Hilpert, K.; Kindrachuk, J.; Zou, Y.; Cheng, J.T.; Kazemzadeh-Narbat, M.; Yu, K.; Wang, R.; Straus, S.K. The biocompatibility and biofilm resistance of implant coatings based on hydrophilic polymer brushes conjugated with antimicrobial peptides. Biomaterials 2011, 32, 3899-3909. [CrossRef]

16. Wang, J.; Li, J.; Guo, G.; Wang, Q.; Tang, J.; Zhao, Y.; Qin, H.; Wahafu, T.; Shen, H.; Liu, X. Silver-nanoparticles-modified biomaterial surface resistant to staphylococcus: New insight into the antimicrobial action of silver. Sci. Rep. 2016, 6, 32699. [CrossRef]

17. Liu, C.; Faria, A.F.; Ma, J.; Elimelech, M. Mitigation of biofilm development on thin-film composite membranes functionalized with zwitterionic polymers and silver nanoparticles. Environ. Sci. Technol. 2016, 51, 182-191. [CrossRef]

18. Al-Jumaili, A.; Mulvey, P.; Kumar, A.; Prasad, K.; Bazaka, K.; Warner, J.; Jacob, M.V. Eco-friendly nanocomposites derived from geranium oil and zinc oxide in one step approach. Sci. Rep. 2019, 9, 5973. [CrossRef]

19. Rahaman, M.S.; Thérien-Aubin, H.; Ben-Sasson, M.; Ober, C.K.; Nielsen, M.; Elimelech, M. Control of biofouling on reverse osmosis polyamide membranes modified with biocidal nanoparticles and antifouling polymer brushes. J. Mater. Chem. B 2014, 2, 1724-1732.

20. Krishnan, S.; Weinman, C.J.; Ober, C.K. Advances in polymers for anti-biofouling surfaces. J. Mater. Chem. 2008, 18, 3405-3413. [CrossRef]

21. Ding, X.; Yang, C.; Lim, T.P.; Hsu, L.Y.; Engler, A.C.; Hedrick, J.L.; Yang, Y.-Y. Antibacterial and antifouling catheter coatings using surface grafted PEG-b-cationic polycarbonate diblock copolymers. Biomaterials 2012, 33, 6593-6603. [CrossRef]

22. Wu, Z.; Chen, H.; Liu, X.; Zhang, Y.; Li, D.; Huang, H. Protein adsorption on poly (N-vinylpyrrolidone)-modified silicon surfaces prepared by surface-initiated atom transfer radical polymerization. Langmuir 2009, 25, 2900-2906. [CrossRef] [PubMed]

23. Irfan, M.; Idris, A.; Yusof, N.M.; Khairuddin, N.F.M.; Akhmal, H. Surface modification and performance enhancement of nano-hybrid f-MWCNT/PVP90/PES hemodialysis membranes. J. Membr. Sci. 2014, 467, 73-84. [CrossRef]

24. Yu, Q.; Zhang, Y.; Wang, H.; Brash, J.; Chen, H. Anti-fouling bioactive surfaces. Acta Biomater. 2011, 7, 1550-1557. [CrossRef] 
25. Abraham, S.; Brahim, S.; Ishihara, K.; Guiseppi-Elie, A. Molecularly engineered p (HEMA)-based hydrogels for implant biochip biocompatibility. Biomaterials 2005, 26, 4767-4778. [CrossRef] [PubMed]

26. Dimitriou, M.D.; Zhou, Z.; Yoo, H.-S.; Killops, K.L.; Finlay, J.A.; Cone, G.; Sundaram, H.S.; Lynd, N.A.; Barteau, K.P.; Campos, L.M. A general approach to controlling the surface composition of poly (ethylene oxide)-based block copolymers for antifouling coatings. Langmuir 2011, 27, 13762-13772. [CrossRef]

27. Gao, Q.; Yu, M.; Su, Y.; Xie, M.; Zhao, X.; Li, P.; Ma, P.X. Rationally designed dual functional block copolymers for bottlebrush-like coatings: In vitro and in vivo antimicrobial, antibiofilm, and antifouling properties. Acta Biomater. 2017, 51, 112-124. [CrossRef]

28. Sawada, I.; Fachrul, R.; Ito, T.; Ohmukai, Y.; Maruyama, T.; Matsuyama, H. Development of a hydrophilic polymer membrane containing silver nanoparticles with both organic antifouling and antibacterial properties. J. Membr. Sci. 2012, 387, 1-6. [CrossRef]

29. Schwartz, V.B.; Thétiot, F.; Ritz, S.; Pütz, S.; Choritz, L.; Lappas, A.; Förch, R.; Landfester, K.; Jonas, U. Antibacterial surface coatings from zinc oxide nanoparticles embedded in poly (n-isopropylacrylamide) hydrogel surface layers. Adv. Funct. Mater. 2012, 22, 2376-2386. [CrossRef]

30. Lotz, A.; Heller, M.; Dohm, N.; Cierniak, P.; Bender, K.; Jansen, B.; Förch, R. Antimicrobial efficacy and optimized cell adhesion from defined plasma polymerised multilayer structures involving zinc acetylacetonate and allylamine. J. Mater. Chem. 2012, 22, 19455-19461. [CrossRef]

31. Xue, C.-H.; Guo, X.-J.; Ma, J.-Z.; Jia, S.-T. Fabrication of robust and antifouling superhydrophobic surfaces via surface-initiated atom transfer radical polymerization. ACS Appl. Mater. Interfaces 2015, 7, 8251-8259. [CrossRef]

32. Kim, E.-S.; Yu, Q.; Deng, B. Plasma surface modification of nanofiltration (NF) thin-film composite (TFC) membranes to improve anti organic fouling. Appl. Surface Sci. 2011, 257, 9863-9871. [CrossRef]

33. Wang, L.; Hu, C.; Shao, L. The antimicrobial activity of nanoparticles: Present situation and prospects for the future. Int. J. Nanomed. 2017, 12, 1227. [CrossRef]

34. Dizaj, S.M.; Lotfipour, F.; Barzegar-Jalali, M.; Zarrintan, M.H.; Adibkia, K. Antimicrobial activity of the metals and metal oxide nanoparticles. Mater. Sci. Eng. C 2014, 44, 278-284. [CrossRef] [PubMed]

35. Palza, H. Antimicrobial polymers with metal nanoparticles. Int. J. Mol. Sci. 2015, 16, 2099-2116. [CrossRef] [PubMed]

36. Jebel, F.S.; Almasi, H. Morphological, physical, antimicrobial and release properties of $\mathrm{ZnO}$ nanoparticles-loaded bacterial cellulose films. Carbohydr. Polym. 2016, 149, 8-19. [CrossRef] [PubMed]

37. Li, N.; Tian, Y.; Zhang, J.; Sun, Z.; Zhao, J.; Zhang, J.; Zuo, W. Precisely-controlled modification of PVDF membranes with 3D TiO2/ZnO nanolayer: Enhanced anti-fouling performance by changing hydrophilicity and photocatalysis under visible light irradiation. J. Membr. Sci. 2017, 528, 359-368. [CrossRef]

38. Chung, Y.T.; Mahmoudi, E.; Mohammad, A.W.; Benamor, A.; Johnson, D.; Hilal, N. Development of polysulfone-nanohybrid membranes using $\mathrm{ZnO}-\mathrm{GO}$ composite for enhanced antifouling and antibacterial control. Desalination 2017, 402, 123-132. [CrossRef]

39. Rajabi, H.; Ghaemi, N.; Madaeni, S.S.; Daraei, P.; Astinchap, B.; Zinadini, S.; Razavizadeh, S.H. Nano-ZnO embedded mixed matrix polyethersulfone (PES) membrane: Influence of nanofiller shape on characterization and fouling resistance. Appl. Surf. Sci. 2015, 349, 66-77. [CrossRef]

40. Al-Naamani, L.; Dobretsov, S.; Dutta, J.; Burgess, J.G. Chitosan-zinc oxide nanocomposite coatings for the prevention of marine biofouling. Chemosphere 2017, 168, 408-417. [CrossRef]

41. Bazaka, K.; Jacob, M.V.; Ivanova, E.P. A study of a retention of antimicrobial activity by plasma polymerized terpinen-4-ol thin films. Mater. Sci. Forum 2010, 654-656, 2261-2264. [CrossRef]

42. Bazaka, K.; Jacob, M.; Truong, V.K.; Crawford, R.J.; Ivanova, E.P. The effect of polyterpenol thin film surfaces on bacterial viability and adhesion. Polymers 2011, 3, 388-404. [CrossRef]

43. Bazaka, K.; Jacob, M.; Truong, V.; Wang, F.; Pushpamali, W.; Wang, J.; Ellis, A.; Berndt, C.; Crawford, R.; Ivanova, E. Effect of plasma-enhanced chemical vapour deposition on the retention of antibacterial activity of terpinen-4-ol. Biomacromolecules 2010, 11, 2016. [CrossRef] [PubMed]

44. Panigrahi, J.; Behera, D.; Mohanty, I.; Subudhi, U.; Nayak, B.B.; Acharya, B.S. Radio frequency plasma enhanced chemical vapor based $\mathrm{ZnO}$ thin film deposition on glass substrate: A novel approach towards antibacterial agent. Appl. Surface Sci. 2011, 258, 304-311. [CrossRef]

45. Kumar, A.; Al-Jumaili, A.; Prasad, K.; Bazaka, K.; Mulvey, P.; Warner, J.; Jacob, M.V. Pulse Plasma Deposition of Terpinen-4-ol: An Insight into Polymerization Mechanism and Enhanced Antibacterial Response of Developed Thin Films. Plasma Chem. Plasma Process. 2020, 40, 339-355. [CrossRef] 
46. Mandakhalikar, K.D.; Rahmat, J.N.; Chiong, E.; Neoh, K.G.; Shen, L.; Tambyah, P.A. Extraction and quantification of biofilm bacteria: Method optimized for urinary catheters. Sci. Rep. 2018, 8, 8069. [CrossRef]

47. Hegemann, D.; Hossain, M.M.; Körner, E.; Balazs, D.J. Macroscopic description of plasma polymerization. Plasma Process. Polym. 2007, 4, 229-238. [CrossRef]

48. Hubert, J.; Vandencasteele, N.; Mertens, J.; Viville, P.; Dufour, T.; Barroo, C.; Visart de Bocarmé, T.; Lazzaroni, R.; Reniers, F. Chemical and physical effects of the carrier gas on the atmospheric pressure PECVD of fluorinated precursors. Plasma Process. Polym. 2015, 12, 1174-1185. [CrossRef]

49. Hegemann, D.; Hossain, M.M. Influence of non-polymerizable gases added during plasma polymerization. Plasma Process. Polym. 2005, 2, 554-562. [CrossRef]

50. Duque, L.; Förch, R. Plasma Polymerization of Zinc Acetyl Acetonate for the Development of a Polymer-based Zinc Release System. Plasma Process.Polym. 2011, 8, 444-451. [CrossRef]

51. Alim, K.A.; Fonoberov, V.A.; Shamsa, M.; Balandin, A.A. Micro-Raman investigation of optical phonons in ZnO nanocrystals. J. Appl. Phys. 2005, 97, 124313. [CrossRef]

52. Golić, D.L.; Branković, G.; Nešić, M.P.; Vojisavljević, K.; Rečnik, A.; Daneu, N.; Bernik, S.; Šćepanović, M.; Poleti, D.; Branković, Z. Structural characterization of self-assembled ZnO nanoparticles obtained by the sol-gel method from Zn (CH3COO) 2. 2H2O. Nanotechnology 2011, 22, 395603. [CrossRef]

53. Alim, K.A.; Fonoberov, V.A.; Balandin, A.A. Origin of the optical phonon frequency shifts in $\mathrm{ZnO}$ quantum dots. Appl. Phys. Lett. 2005, 86, 053103. [CrossRef]

54. Rajalakshmi, M.; Arora, A.K.; Bendre, B.; Mahamuni, S. Optical phonon confinement in zinc oxide nanoparticles. J. Appl. Phys. 2000, 87, 2445-2448. [CrossRef]

55. Yahia, S.B.; Znaidi, L.; Kanaev, A.; Petitet, J. Raman study of oriented ZnO thin films deposited by sol-gel method. Spectrochim. Acta Part. A Mol. Biomol. Spectrosc. 2008, 71, 1234-1238. [CrossRef] [PubMed]

56. Gliemann, G.K. Nakamoto: Infrared and Raman Spectra of Inorganic and Coordination Compounds. Bericht. Bunsengesellsch. Phys. Chem. 1978, 82, 1263. [CrossRef]

57. Yang, R.D.; Tripathy, S.; Li, Y.; Sue, H.-J. Photoluminescence and micro-Raman scattering in ZnO nanoparticles: The influence of acetate adsorption. Chem. Phys. Lett. 2005, 411, 150-154. [CrossRef]

58. Soofivand, F.; Salavati-Niasari, M.; Mohandes, F. Novel precursor-assisted synthesis and characterization of zinc oxide nanoparticles/nanofibers. Mater. Lett. 2013, 98, 55-58. [CrossRef]

59. Schneider, J.J.; Hoffmann, R.C.; Engstler, J.; Klyszcz, A.; Erdem, E.; Jakes, P.; Eichel, R.-A.; Pitta-Bauermann, L.; Bill, J. Synthesis, characterization, defect chemistry, and FET properties of microwave-derived nanoscaled zinc oxide. Chem. Mater. 2010, 22, 2203-2212. [CrossRef]

60. Arii, T.; Kishi, A. Humidity controlled thermal analysis. J. Therm. Anal. Calorim. 2006, 83, 253-260. [CrossRef]

61. Wang, Z.; Zhan, X.; Wang, Y.; Muhammad, S.; Huang, Y.; He, J. A flexible UV nanosensor based on reduced graphene oxide decorated $\mathrm{ZnO}$ nanostructures. Nanoscale 2012, 4, 2678-2684. [CrossRef]

62. Lizundia, E.; Ruiz-Rubio, L.; Vilas, J.L.; León, L.M. Poly (l-lactide)/zno nanocomposites as efficient UV-shielding coatings for packaging applications. J. Appl. Polym. Sci. 2016, 133, 42626. [CrossRef]

63. Bazaka, K.; Jacob, M.V. Post-deposition ageing reactions of plasma derived polyterpenol thin films. Polym. Degrad. Stab. 2010, 95, 1123-1128. [CrossRef]

64. Xie, Y.; He, Y.; Irwin, P.L.; Jin, T.; Shi, X. Antibacterial activity and mechanism of action of zinc oxide nanoparticles against Campylobacter jejuni. Appl. Environ. Microbiol. 2011, 77, 2325-2331. [CrossRef]

65. Zhang, L.; Jiang, Y.; Ding, Y.; Daskalakis, N.; Jeuken, L.; Povey, M.; O’Neill, A.J.; York, D.W. Mechanistic investigation into antibacterial behaviour of suspensions of $\mathrm{ZnO}$ nanoparticles against $\mathrm{E}$. coli. J. Nanopart. Res. 2010, 12, 1625-1636. [CrossRef]

66. Oussalah, M.; Caillet, S.; Saucier, L.; Lacroix, M. Inhibitory effects of selected plant essential oils on the growth of four pathogenic bacteria: E. coli O157: H7, Salmonella typhimurium, Staphylococcus aureus and Listeria monocytogenes. Food Control. 2007, 18, 414-420.

67. Cox, S.; Mann, C.; Markham, J.; Bell, H.; Gustafson, J.; Warmington, J.; Wyllie, S. The mode of antimicrobial action of the essential oil of Melaleuca alternifolia (tea tree oil). J. Appl. Microbiol. 2000, 88, 170-175. [CrossRef]

(C) 2020 by the authors. Licensee MDPI, Basel, Switzerland. This article is an open access article distributed under the terms and conditions of the Creative Commons Attribution (CC BY) license (http://creativecommons.org/licenses/by/4.0/). 